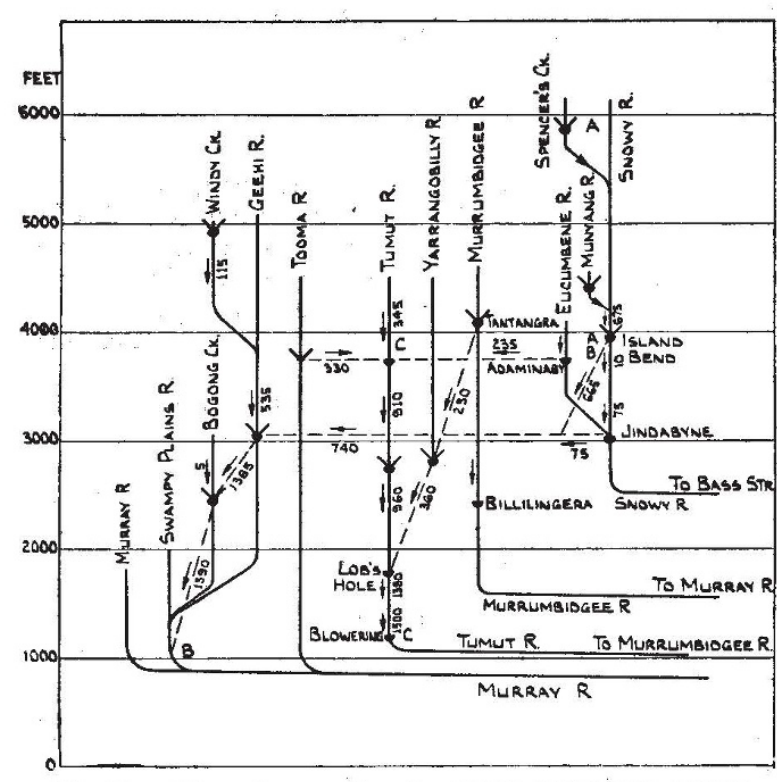

Fig. 2. Flow diagram for Snowy-Murray-Tumut scheme Figures represent average flow in thousands of acre feet per annum.

Dams and collection points ; racelines ; diversion tunnels Murray ; $C C$, Tumut

Murray-Tumut scheme. In the alternative scheme, the annual flow in the Snowy-Murray diversion tunnel would be reduced by 410,000 acre feet, a similar amount being diverted from Jindabyne Dam, on the Snowy, to Billilingera Dam, on the Murrum. bidgee.

The total average power potential may be determined from the average flow at each dam or pond and its height above the point where the river ceases to fall rapidly. In the former scheme, the power potential in each of the three generating systems is thus approximately as follows: (a) Upper Snowy: $50,000 \mathrm{~kW}$. (b) Snowy-Murray diversion (Snowy R., Geehi R., and Bogong Creek): $430,000 \mathrm{~kW}$. (c) Tumut (Eucumbene, Tooma, Tumut and Yarrangobilly Rivers): $410,000 \mathrm{~kW}$. The three systems have therefore a continuous power potential of $890,000 \mathrm{~kW}$. In the alternative scheme, the diversion of 410,000 acre feet per annum to the Murrumbidgee would cause a loss of about $60,000 \mathrm{~kW}$., but would have certain compensating advantages.

Having in mind the load factors at which the various power stations will operate when interconnected with existing and future generating stations in New South Wales, Victoria and the Federal Capital Territory, the proposals involve the installation of generating plant of $1,720,000 \mathrm{~kW}$. capacity in the case of the Snowy-Murray-Tumut scheme, or $1,565,000 \mathrm{~kW}$. in the alternative scheme.

The above analysis is based on data provided through the courtesy of the chairman of the Snowy River Committee, Mr. L. F. Loder, and used by the Committee in formulating its 1948 report. The whole area is relatively undeveloped, and it is accepted that the figures adopted are liable to modification when a more detailed survey has been made.

The magnitude of the scheme is indicated by the extent of the engineering works to be put in hand, involving the construction of more than eighty miles of tunnel and about five hundred miles of racelines. In addition, either of the alternative schemes will require the construction of seven major dams, some of them in country which has been hitherto regarded as fairly inaccessible. It is anticipated that the construction of the entire project will take some thirty years, but the benefits of the scheme will become progressively available during that time.

From the irrigation point of view, the water will be used to reinforce and extend the existing areas on the Murrumbidgee and Murray. These areas support very diverse forms of production, from dried fruits, citrus and canned fruits, and wine grapes, through irrigated pastures used for dairying or fat lambs, to rice and summer forages. In dry seasons considerable volumes are used to help crops of winter forage and grain. The allocation of water is through a system of 'rights' for which the landholder has to pay; extra supplies can also be purchased in some years. The right may be the equivalent of one foot of irrigation water over the whole holding, or may be one quarter to one tenth of a foot, depending on the nature and situation of the land. The landholder has to plan his type of production according to the size of his holding and his watter-right, as various crops require various amounts; rice needs six feet, and winter forages perhaps only six or eight inches of water.

Soil problems are frequent in these areas, as the experiences of the last half-century have shown. Nowadays it is generally accepted that a more or less intensive soil survey is essential before any irrigation scheme is planned. Although some soil problems of irrigated land have not yet been solved, there is sufficient background of scientific knowledge available to ensure their satisfactory solution.

Sociologically, the more intensive the use of water, the closer will be the settlement of the land, and the larger the local units of population which can be established. Given effective leadership, such units can be more readily provided with the basic amenities which have not always been characteristic of rural areas. On the other hand, the forms of produce which lead to closest settlement, such as dried, canned and fresh fruits, and wine, are already available far in excess of Australian requirements, while the future of dairy products is uncertain. It therefore seems desirable that the water should be used to stimulate meat production and the growth of forages as reserves against the droughts which periodically afflict large areas. In this connexion it would be possible to irrigate localized areas in regions with an average rainfall of as low as 9 in. and a high degree of variability. However, this would mean passing the water down long stretches of river, with corresponding increases in the percentage lost through seepage and evaporation. The allocation of the water will thus become a very complicated problem, in the solution of which local interests must give place to the overall needs of the community.

\section{RECENT ADVANCES IN FERMENTATION RESEARCH}

A SYMPOSIUM/on " lokecent Advances in the A Fermentati 6 -Indud tries" was arranged by the Scottish Sechops of the Pbyal|Institute of Chemistry as a parl of ageneral proghambe of scientific courses, eorferen ss $^{*}$ and symposia, and held at the University of Sit. Andrews during July 23-30. At a previous symposium in 1947, also held at St. Andrews, the 


\section{No. 4167 September 10, $1949 \quad$ N A T URE}

papers ranged over the field of recent developments in industrial organic chemistry. It was now felt that the fermentation industries should be similarly treated. It must be said that the organisers of the symposium stretched their net wide and such diverse subjects as panary fermentation, potable fermentation products, industrial fermentations, mould metabolic products and methods of assay of amino-acids and penicillin were discussed.

The members of the symposium were welcomed to St. Andrews by the Principal of the University, Sir James Irvine; immediately thereafter the congress proceeded to business with the reading of papers.

The organisers of the symposium did not make the usual mistake of trying to include too much. Each speaker was allotted an hour for his paper and fifteen minutes was reserved for discussion. Another excellent feature of the symposium was the fact that there were no afternoon sessions, and members were free to do as they pleased and possibly digest what they had heard in the morning. There was generally an evening session during 6-7.15 p.m.

The first paper was by Dr. A. Olsen (Standard Yeast Co., Ltd.) with the very wide title "Yeast". The author, however, limited himself to the discussion of problems connected with the production of bakers' yeast. One of the chief problems confronting the manufacture of bakers' yeast is the suppression of alcohol formation, and this is mainly brought about by vigorous aeration of the actively fermenting cultures. The actual process of largescale manufacture, with all its necessary controls of sterilization and cooling, was described in detail. The qualities of a good bakers' yeast were also discussed. Such a yeast must be capable of good gas production in a dough. It must have a good, light colour and emulsify easily with water. The baker must have a yeast which maintains its quality from week to week and year to year. The action of yeast on flour is not a simple one of carbon dioxide production as is usually supposed. There are other and complex factors involved, which are still little understood. For example, there is the question of the maturing action of yeast proteins on gluten. Apparently, brewers' yeast is unsuitable for this purpose.

In the second paper, Dr. I. A. Preece (Heriot-Watt College, Edinburgh) gave an account of the materials encountered in malting and brewing, with special reference to the carbohydrate side of the problem and the behaviour of the $\alpha$ - and $\beta$-amylases in the mashing process. This is a province which Dr. Preece has made particularly his own, and a very clear picture of the complex reactions as known at present was given. A point in the mashing process to which brewers should give attention is the heat sensitivity of $\beta$-amylase. Thus, an increase from, say, $65^{\circ}$ to $67^{\circ} \mathrm{C}$. $\left(149-153^{\circ} \mathrm{F}\right.$.) would have but little influence on $\alpha$-amylolysis, whereas it would considerably restrict $\beta$-amylase activity and thereby markedly decrease the proportion of maltose and thus of total fermentable sugar in wort.

The evening session was addressed by Dr. D. W. Kent-Jones on panary fermentation. With great respect to all the other speakers, this was certainly the best delivered and most entertaining of all the papers of the symposium. We may not have learnt much about panary fermentation, but we did learn a great deal about the troubles that afflict the unfortunate baker in his daily efforts with the complex biochemical experiment of baking, to obtain a satisfactory and palatable loaf pleasing to his public. The author dealt in detail with the fundamental work on dough properties as well as fermentation changes in dough brought about by yeast. The important question of 'ripeness' of a dough was also discussed.

Dr. L. R. Bishop (Stag Brewery, London) discussed the nitrogenous constituents of brewing materials, for example, proteins and amino-acids. An account was given of the nature of the proteins in wort and their connexion with the phenomenon of 'haze' in beer. A description was also given of the absorption of amino-acids from wort by yeast.

A particularly interesting paper was read by Dr. Erik Helm (Alfred Jorgensen Laboratory of Fermentology, Copenhagen, Denmark) on a comparison of British and Continental methods of brewing. The two systems differ in a number of particulars. In the first place, a 'top' yeast, in which the major portion of the yeast rises to the surface of the fermenting wort, is used in British brewing systems, whereas on the Continent a 'bottom' yeast is employed in which the yeast sinks to the bottom of the fermenting vessel at the close of fermentation. In the second place, the temperatures at which fermentation is carried out in the two systems are very different. On the Continent low temperatures $\left(6-11^{\circ}\right.$ C.) are used, whereas in British top-fermentation brewing relatively high temperatures prevail $\left(18-22^{\circ} \mathrm{C}\right.$.). The methods of mashing are also different. The British system uses a wort prepared by an infusion process, while on the Continent a decoction method is followed. With these differences in mind, Dr. Helm discussed certain aspects of the nitrogen changes in the two systems; particularly with regard to the total amount of amino-nitrogen taken up from the wort, which is very much less in bottom fermentation systems than in top fermentation brewing. There are also differences in behaviour in the absorption of individual amino-acids, such as methionine, which is completely absorbed in twenty-four hours by 'top' yeasts, whereas it only gradually disappears in bottom fermentation.

In the Industrial Fermentations Section the production of industrial alcohol from molasses was described by Dr. E. R. Dawson (The Distillers Co., Ltd.). The period between the two World Wars has seen striking developments in the type and purity of the yeast used for molasses fermentation and also in the type of fermentation plant employed. Strains of yeast are now selected which are not only capable of tolerating high concentrations of alcohol but also maintain their stable and uniform characteristics. In recent years three principal lines of progress in the fermentation of molasses for the production of alcohol have been developed, namely, the development of continuous fermentation processes, methods for improving the medium prior to fermentation, and the recovery of the yeast at the end of fermentation and its use in subsequent fermentations.

Acetone-butanol fermentations were discussed in great detail by Mr. E. Gill (Commercial Solvents (Great Britain), Ltd.) and other industrial fermentations such as the production of $2: 3$ butylene glycol and glycerol were described by Dr. G. G. Freeman (Nobel Division, Imperial Chemical Industries, Ltd.). Other fermentations, for example, acetoin (acetylmethyl carbinol) were also briefly discussed. So far as the $2: 3$ butylene glycol fermentation is concerned, recent work has established the existence of three distinct fermentations brought about by three different organisms, Aerobacter aerogenes, which fer- 
ments hexoses yielding a mixture of $d$ - and mesoisomers of the glycol, in which the meso-isomeride is the main product; Aerobacillus polymyxa, which ferments starches and dilute sugar solutions to yield $l-2: 3$ butylene glycol and ethanol; and lastly, Aeromonas hydrophila, which gives rise to $l$ - and meso-2: 3 butylene glycol isomers; while ethanol and lactic acid are the main non-gaseous products. A description was also given of the various methods of glycerol production from modified alcoholic fermentation. The mechanism of glycerol production was also discussed, together with the practical details of isolating the product from the fermented liquors.

The use of fungal amylase in the industrial production of alcohol and alcoholic products was discussed by Dr. R. W. Jackson (Northern Regional Research Laboratory, U.S. Dept. of Agriculture, Peoria, Illinois). The heavy demand in the United States for alcohol production during the Second World War led to the investigation of various methods of starch conversion to fermentable sugars. The amylases produced by moulds were found to be efficient converting agents - a fact that has been known for many years. A wide survey was made of different moulds which included 350 strains belonging to forty species of five different genera. In actual practice, two strains of Aspergillus niger were most used in this work. The amylase system of moulds was found to consist of $\alpha$-amylase alone; no $\beta$-amylase being present. This $\alpha$-amylase differs in some respects from malt $\alpha$-amylase ; for example, it does not liquefy starch as rapidly, and, furthermore, it is more thermolabile. Although fungal- $\alpha$-amylase is essential for saccharification of starch, alcohol yield was found to be better correlated with another enzyme which has been termed 'maltase'. This maltase hydrolyses maltose and higher glucose polymers to glucose. The amounts of maltase and $\alpha$-amylase show considerable variation from one mould to another. The fungal system was also found to be capable of hydrolysing the $\alpha-1: 6$ glucosidic linkage of isomaltose. A wide range of starches from different sources, for example, maize, wheat, sorghum and potatoes, are attacked by fungal amylase.

The third and last session of the symposium was concerned with microbiological advances, and was under the chairmanship of Prof. W. H. Everett. Dr. J. H. Birkinshaw (London School of Hygiene and Tropical Medicine) described various aspects of fungal metabolism with special reference to the major pro. ducts of fermentation of Aspergillus and Penicillium species, namely, oxalic and eitric acids. The discovery of the production of citric acid by Aspergillus species has now been developed into an industrial process of considerable commercial importance. Moulds, however, are capable of producing a very wide range of complex metabolic products which include not only aliphatic but also aromatic and heterocyclic derivatives. For example, among the aromatic products of mould metabolism, a whole series of phenols and phenolic acids of varying degrees of complexity are encountered. Some of these substances can be regarded as being based upon 2:4 dihydroxybenzoic acids, whereas others are $p$-quinols and thus closely related to the benzoquinones which are also produced by mould metabolic activity. There is strong evidence for the view that the quinols and their corresponding quinones, which frequently occur together, form an oxidation-reduction system which is intimately con. nected with the respiratory system of the mould cell. Even more complex compounds than phenols and phenolic acids have been met as mould metabolic products. For example, a number of hydroxyantha. quinones have been isolated from fungi, but oddly enough, only one example of a naphaquinone has been found. Dr. Birkinshaw also referred to the pro. duction of compounds by moulds which contain other elements besides carbon, hydrogen and oxygen, for example, nitrogen, sulphur and chlorine, in their molecules. Fungal antibodies of known structure are examples of this type of compound which have proved their value in chemotherapy, and are therefore of great importance in the medicinal chemical industry.

The question of microbiological assay of aminoacids was discussed by the present writer. Nicrobiological assays of amino-acids have a number of advantages over chemical methods because they are relatively rapid to carry out and do not require expensive and elaborate apparatus. Undoubtedly one great advantage of microbiological assay methods over chemical determinations lies in the fact that in a mixture of leucine and isoleucine differentiation is specific and exact. Up to the present time no chemical method of estimation has been devised which is capable of giving accurate values for these two amino-acids when present together.

An interesting paper on the assay of penicillin with particular reference to the micro-chromatographic technique was read by Mr. C. R. Bond (Dyestuffs Division, Imperial Chemical Industries, Ltd.). The assay of penicillin really resolves itself into two parts : (1) the determination of total penicillin, and (2) the determination of the relative amounts of the individual penicillins, because penicillin as produced by suitable types of mould consists of at least ten acids which possess the same characteristic structure with difierent side-chains. Mr. Bond described the various methods for estimating total penicillins in the form of total anti-bacterial activity against a specific organism by micro-biological methods. A critical evaluation was then given of the various methods which have been suggested for the assay of the purer forms of penicillin and for the determination of individual penicillins themselves, such as the iodimetric method, counter-current distribution methods and the paper strip method, which makes use of distribution between two solvents. This last method embodies the micro-chromatography of a trace of sample on a bufiered filter paper strip fol. lowed by mounting of the strip on an inoculated agar plate. After incubation, inhibition zones due to the different penicillins are produced in the agar around the paper strip, and from them the relative amounts of the individual penicillins can be calculated.

The final paper to the symposium was contributed by Mr. A. Parker (Dyestuffs Division, Imperial Chemical Industries, Ltd.) on aseptic technique in industrial-scale fermentation. This subject, of course, is of especial importance in the large-scale manufacture of such products as penicillin. A close approach has been made to this ideal by the design and operation of the plant. Thus 'seed' cultures are prepared so that all possibilities of contamination are guarded against. Again, the plant itself must be capable of complete sterilization and must be so devised as to exclude all contaminants.

The Friday and Saturday of the symposium week synchronized with meetings of the Biochemical and Physiological Societies at Dundee and St. Andrews respectively. The social side of the symposium was not neglected and visits were arranged to various places of interest.
E. BARTON-WRIGHT 